\title{
Variability and Predictability of Large-Scale Wind Energy in the Netherlands
}

\author{
A.J. Brand, M. Gibescu and W.W. de Boer \\ Energy research Centre of the Netherlands, Delft University of Technology \& KEMA \\ Netherlands
}

\section{Introduction}

This chapter presents in a national context energy balancing requirements due to the variability and the limited predictability of wind energy in the thermal energy system of the Netherlands. In addition options to reduce these requirements are discussed. To this end 7.8 GW of wind power capacity in a system with $35 \mathrm{GW}$ of total capacity is considered. The balancing requirements due to the cross-border flow of wind energy (export of domestic wind energy or import of foreign wind energy) however are not covered as these require an international context (ETSO, 2008). In addition the potential benefits of an intra-day market are not explored.

This chapter is organized as follows. First, section 2 presents various scenarios for wind and other energy capacity in the Netherlands, and introduces the structure of the Dutch electricity market. Next, section 3 gives a short overview of studies which addressed balancing energy reduction options in the contexts of the electricity markets in Denmark, Germany and Spain. Section 4 continues with the modeling of wind variability and wind predictability and its relevance to wind energy integration. Sections 5 and 6 then present the balancing energy requirements due to wind variability and limited wind predictability. Subsequently, section 7 discusses options to reduce the extra balancing energy requirements, which options include short-term forecast updates, aggregation, pumped storage, compressed air energy storage, fast start-up units, inverse offshore pump accumulation system, and wind farm shut-down strategies. Finally, section 8 summarizes the results.

\section{Energy scenarios and market structure}

\subsection{Synopsis}

In order to study balancing energy requirements in the future in the Netherlands, various energy scenarios were developed. These are presented in section 2.2, with attention for wind energy production capacity (paragraph 2.2.1), total electricity production capacity (paragraph 2.2.2), and flexibility of production (paragraph 2.2.3). The future structure of the Dutch electricity market is presented in section 2.3. The material in this section has been published in greater detail in de Boer et al., 2007; Gibescu et al., 2008b; and Gibescu et al., 2009. 


\subsection{Energy scenarios}

\subsubsection{Wind energy capacity}

Offshore wind energy growth scenarios were developed that are consistent with the renewable policy goals in the Netherlands over the period up to the year 2020. Based on these rough estimates, on the onshore wind farm placement in the year 2006, and on the pending applications for environmental permits for offshore wind farms, the most likely locations and installed capacities were chosen for the years 2010, 2015 and 2020. In addition, three offshore wind energy scenarios were created: Low, Basic and Advanced. Only one scenario was created for onshore wind installed capacity. The scenarios are summarized in table 1.

\begin{tabular}{|l|r|l|l|}
\hline & & Year & \\
\hline & 2010 & 2015 & 2020 \\
\hline Low Offshore & 720 & 2010 & 3800 \\
\hline Basic Offshore & 1180 & 3110 & 6030 \\
\hline Advanced Offshore & 1520 & 4110 & 8000 \\
\hline Onshore & 1750 & 1800 & 1800 \\
\hline
\end{tabular}

Table 1. Scenarios for offshore and onshore wind capacity in MW in the Netherlands

The aim of the Dutch government (from the 2004 policy) was to have $20 \%$ of demand served with help of renewable energy in the year 2020. The scenario Advanced will cover this completely with wind energy (given capacity factors of $25 \%$ and $37 \%$ respectively for onshore and offshore). Since this is an optimistic view of wind energy growth, the Basic scenario is employed in this study.

The offshore locations of wind farms for the scenario Basic Offshore 2020 were derived from the requests for permits for wind farms in the North Sea as filed by early 2006.

\subsubsection{Total electricity capacity}

Scenarios for the total electricity capacity in the Netherlands were developed by considering the total production plant in the year 2005, and estimating the retirement and addition of plant by the years 2010-2015-2020. The resulting total capacity break-up for the year 2020 is shown in table 2.

\begin{tabular}{|c|c|c|c|c|c|c|}
\hline \multicolumn{7}{|c|}{ Production in the Netherlands for several scenarios } \\
\hline & 2005 & & & 2020 & & \\
\hline \multirow[t]{2}{*}{ Type of power production } & $\begin{array}{c}\text { KEMA } \\
\text { database }\end{array}$ & $\begin{array}{c}\text { basic } \\
\text { scenario }\end{array}$ & $\begin{array}{c}\text { gas } \\
\text { scenario }\end{array}$ & $\begin{array}{c}\text { coal } \\
\text { scenario }\end{array}$ & $\begin{array}{c}\text { high } \\
\text { growth } \\
\text { scenario }\end{array}$ & $\begin{array}{c}\text { low } \\
\text { growth } \\
\text { scenario }\end{array}$ \\
\hline & MW & $\mathrm{MW}$ & $\mathrm{MW}$ & $\mathrm{MW}$ & $\mathrm{MW}$ & $\mathrm{MW}$ \\
\hline Gas motor & 1.450 & 1.950 & 1.950 & 1.950 & 2.260 & 1.680 \\
\hline Gas turbine & 890 & 1.200 & 1.200 & 1.200 & 1.390 & 1.040 \\
\hline STAG of Combi & 11.690 & 17.470 & 18.920 & 15.570 & 19.950 & 15.310 \\
\hline Conventional: boiler + ST (gas) & 2.100 & 360 & 360 & 360 & 360 & 360 \\
\hline Conventional: boiler + ST (coal) & 4.180 & 5.630 & 4.180 & 7.530 & 6.510 & 4.850 \\
\hline Nuclear & 450 & 450 & 450 & 450 & 450 & 450 \\
\hline Waste and biomass & 390 & 520 & 520 & 520 & 610 & 450 \\
\hline Wind & 390 & 7.800 & 7.800 & 7.800 & 10.400 & 4.800 \\
\hline Total production & 21.540 & 35.380 & 35.380 & 35.380 & 41.930 & 28.940 \\
\hline
\end{tabular}

Table 2. Installed power in the Netherlands for several growth scenarios in 2020 
As to the conventional production, on basis of the current practice, it is assumed that power plants can operate at $150 \%$ in respect to the original design. Their capacity is expected to decrease from $21 \mathrm{GW}$ in the year 2005 to $9 \mathrm{GW}$ in the year 2020. In addition, it is expected that most of the coal fired power plants and gas-fired combined cycle plants are still operating in the year 2020.

As to new production capacity five scenarios - each covering the years 2010-2015-2020 were set up: basic, gas, coal, high growth, and low growth. The following parameters were considered: economic growth (respectively 1, 2 and 3\% per year), fuel mix (basic scenario with current gas-to-coal ratio 1.0:3.5, a gas-and-coal reign scenario), and intensity of wind energy (see section 2.2.1).

In the basic scenario the control capabilities will be dominated the Combined Heat and Power (CHP) plants because the major growth of the capacity will most probably come from these plant. Power plants build after the year 2000 have better control capabilities: $\sim 8 \%$ of nominal power per minute for gas, and $\sim 3 \% / \mathrm{min}$ for coal. The range of power change capability for CHP plants is $50 \%$ or more.

In the other scenarios the control capabilities differ slightly. For the coal scenario the rate of power change capabilities will be somewhat lower and for the gas scenario it will slightly higher.

\subsubsection{Flexibility of production}

Flexibility of production is required in order to follow the expected wind power variations, and to compensate unexpected wind power variations. This warrants a certain margin and rate of change capability, primary for the Programme Responsible Parties (PRPs) and secondly for the Transmission System Operator (TSO). The flexibility of production is defined in terms of: rate of change of the total capacity, amount of regulating (i.e. spinning) power and reserve power, rate of change of the spinning reserve units, and start time of the remaining units that are not delivering power during the load following cycle. Most of these terms depend on the operating point in the load following cycle and on the types of power units operating in that operating point.

A maximal ramping capability of $8 \% \mathrm{P}_{\text {nom }} / \mathrm{min}$ is expected for gas-fired units and $3 \%$ for coal-fired units. In the year 2020 the morning shoulder (i.e. the difference between off-peak and peak load) is expected to cover approximately $10 \mathrm{GW}$ with a maximal required ramp rate of $60 \mathrm{MW} / \mathrm{min}$. The gas fired power units are expected to carry this ramping load. This implies that a minimum of $10 \mathrm{GW}$ of gas-fired units have to be spinning. If they have an average rate of change of $4 \% / \mathrm{min}$, then $400 \mathrm{MW} / \mathrm{min}$ can become available. This is enough to handle the expected variability due to load.

\subsection{Structure of the electricity market}

In the Netherlands wind power has been fully integrated in the day-ahead and imbalance market structures since the year 2001, and this situation is not expected to change in the future. Market participants known as Programme Responsible Parties (PRPs), governing a portfolio consisting of both renewable and conventional energy resources, submit to the Transmission System Operator (TSO) balanced schedules for energy delivered to and absorbed from the system during a 15-minute interval known as Programme Time Unit (PTU). This arrangement provides some insulation from the full exposure to imbalance charges for the wind producer, as conventional units in the PRP's portfolio may act to correct energy programme deviations due to wind variability and limited predictability. 


\section{International experience}

\subsection{Overview}

This section presents a short overview of studies on balancing energy reduction options in the contexts of the electricity markets in Denmark, Germany and Spain. Section 3.2 starts with a short survey of international experiences with instruments for balancing the variability and forecasting errors introduced by large-scale wind energy in a power system. The focus is on wind power forecast updates (paragraph 3.2.1), aggregation of wind power (paragraph 3.2.2), energy storage (paragraph 3.2.3), and wind farm control (paragraph 3.2.4). In addition, the design of balancing markets is addressed in subsection 3.3.

\subsection{Technology}

\subsubsection{Wind power forecast updates}

The quality of wind power forecasts significantly improves as the forecast horizon decreases (Lange and Focken, 2005). The state-of-the-art indicates that the capacity normalized root mean square error (cRMSE) may reach a minimum value of $2 . . .3 \%$ for a lead time of 2 hours before delivery (Krauss et al., 2006). For example in Germany this significant improvement in the accuracy of wind power forecasts consequently allowed for a better commitment and dispatch of the other generation units (Krauss et al., 2006). By doing so, the reserves held for wind power were decreased and the resulting surplus power could be offered by the conventional units in for example the intra-day market. Also a more efficient use was made of the available ramping capabilities of different units.

\subsubsection{Aggregation of wind power}

Aggregation of wind power over a larger geographical area, apart from smoothing out variability, improves the quality of the forecast because of the partly uncorrelated character of the forecast errors (Lange \& Focken, 2005; von Bremen et al., 2006). As a result, both the reserves held and the reserves actually applied in a control area are decreased. Balancing wind power across control areas is even more efficient (Krauss et al., 2006).

\subsubsection{Energy storage}

Due to the relatively high investment costs of large-scale energy storage technologies, storage has to be multi-functional and market-driven, rather than employed only in order to reduce imbalances resulting from wind energy.

In the Netherlands, several studies were devoted to cost-benefit analysis for large scale energy storage systems (Ummels et al., 2008; de Boer et al., 2007). In particular an energy storage system has been proposed that would provide the following functions (de Boer et al, 2007):

- Download capacity for wind power at night during high wind and light load periods;

- Download capacity at night for base-load units that cannot be switched off, coupled with additional production capacity during peak load;

- Extra production capacity during periods with cooling water discharge restrictions for conventional plants; and

- Primary action.

Section 7.4 describes the benefits of such a system when it is used to perform the first function. 


\subsubsection{Wind farm control}

Although in a technical sense clustering of wind farms into a virtual power plant may provide benefits for active power management and reactive power control, it is not economically attractive to operate such a plant for power balancing if the market design penalizes curtailment, as shown in Germany (Wolff et al., 2006). However, occasional use of wind farms to provide downward regulating power may be attractive during certain periods, e.g. when the surplus price is negative.

\subsection{Balancing market design}

As to the market design for balancing services, there are major differences between various countries (Verhaegen et al., 2006), where each market design has an unique impact on how balancing is actually provided. For example, there are differences in the institutional environment where the responsibility for taking care of imbalances arising from wind power either is assigned to a system operator (Germany, Spain, and Denmark for onshore wind power) or to a market party (the Netherlands, United Kingdom and Denmark for offshore wind power). Also, differences exist in the rules of use and provision of balancing services. In the following a number of developments are listed.

In the past years progress has been made to increase the liquidity of intra-day markets. Gate closure times of about one hour ahead of delivery (such as in the Netherlands) are sufficient to increase the accuracy of wind energy predictions to an acceptable level. This is in addition to the single-buyer balancing market, which is operated by the Transmission System Operator (TSO).

Power systems with dual imbalance pricing are problematic for wind energy due to the high penalties imposed, e.g. in the United Kingdom. To minimize imbalance costs, market parties should aggregate their production portfolios (Gibescu et al., 2008a).

If market parties employ wind power forecasts without being made responsible for balancing, their aim would be to optimize financial gains rather than to minimize their imbalance. This is why in such cases aggregated wind power forecasts have to be managed by the TSO.

There is a clear trend in Europe towards more cross-border balancing, which certainly promises advantages for wind power (Verhaegen et al., 2006). Balancing geographically larger control areas will provide benefits for wind power, not only because of overall decreased variability and increased predictability, but also because of larger market volumes and larger balancing resources.

Finally it is noted that in all European countries the present organization of support schemes - which to date remains the major source of revenues for wind power producers discourages the use of curtailment as a balancing instrument. Controlling the power output of wind farms must therefore be considered as an option from a power system operations perspective, since the opportunity loss by curtailment is significant.

\section{Wind modeling aspects of wind energy integration}

\subsection{Outline}

This section presents the modeling of wind variability and wind predictability and its relevance to wind energy integration. First, section 4.2 critically reviews existing methods to generate wind power time series for integration studies. Next, the sections 4.3 and 4.4 present a new method to create measured respectively forecasted wind speed time series. And finally in section 4.5 the method to create wind power time series is explained. The 
methods described in the sections 4.3-4.5 were developed for this purpose by the authors (Brand, 2006; Gibescu et al., 2006; Gibescu et al., 2009).

\subsection{Existing methods}

A wind power integration study requires wind power time series originating from wind speed time series, where wind speed comprises measured and forecasted data. In addition the spatial correlation of wind speeds between sites must be taken into account because, as wind farms will be concentrated in areas with favorable wind conditions, their outputs will be strongly correlated. The resulting cross-correlations are essential when assessing the system-wide variability and predictability in large-scale wind production, and in turn affect the system requirements for reserve and regulation energy.

Three different methods to generate wind time series can be identified, namely by using actually measured wind speed time series, by using synthesized wind time series data (Doherty \& O'Malley, 2005), or by using a combination of measured and synthesized wind speed time series (Giebel, 2000; Holttinen, 2005; Norgard et al., 2004). Valued against the requirements for integration studies these methods fall short for the creation of both realistic measured and forecasted wind power time series.

In order to correctly account for the spatial and temporal correlations of wind in an area, the method in section 4.3 derives the relevant statistical properties of the interpolated series from measured wind speeds. To this end assumptions are made only regarding the Markov property and the exponential decay of covariance with distance. In addition, this method uses 15-minute averaged wind speed in order to accurately model the balancing market in the Netherlands.

Two methods to generate wind forecasts can be identified, namely by using real wind forecasts (Lange \& Focken, 2005) or by using synthesized wind forecasts (Norgard et al., 2004; Söder, 2004).

In order to correctly account for the limitations in a forecasting method and for the degree of uncertainty, in section 4.4 real wind forecasts are used. Unlike the alternative, this approach does not require assumptions on the distribution, correlation and increase of wind speed forecasting errors.

\subsection{Measured wind speed \\ 4.3.1 Historical wind data}

Wind speed was modeled using historical wind data. To this end wind speed data sets were obtained from the Royal Dutch Meteorological Institute (KNMI). The data comprise 10minute wind speed averages with a resolution of $0.1 \mathrm{~m} / \mathrm{s}$ for 16 locations in the Netherlands and its coastal waters (six onshore, four coastal and six offshore; see figure 1) measured between 31 May 2004 and 1 June 2005. In addition, 10-minute wind speed standard deviations are available for the onshore locations and are estimated for the offshore locations. (The standard deviations are used in the height transformation in section 4.3.2.) The chosen time series reflects the spatial distribution of present and future installed wind power in the Netherlands.

\subsubsection{Height transformation}

Sensor height where wind speed was measured may differ between locations. The standard method to transform to hub height is to employ the logarithmic vertical wind speed profile 


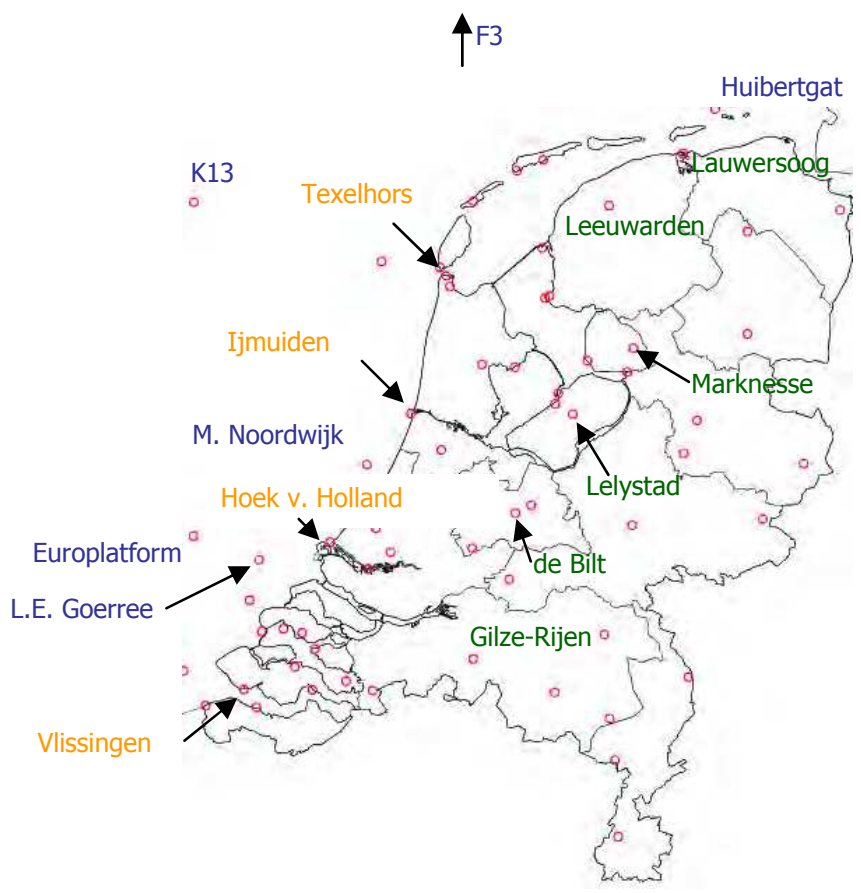

Fig. 1. Onshore, coastal and offshore wind speed measurement sites in this study

in combination with the surface roughness length (e.g. Walker \& Jenkins, 1997). The local surface roughness length however is difficult to estimate. For this reason Brand, 2006, has eliminated this need. Instead, two location-dependent parameters are used: the friction velocity $u_{*}$ and the average Monin-Obukhov length $L_{\text {esti. }}$. The friction velocity is estimated from the 10-minute wind speed standard deviation which for most locations is available. If not, for an offshore location the friction velocity is estimated from the vertical wind speed profile. The Monin-Obukhov length is estimated by the average value that follows from the positive average heat flux that has been found over the North Sea and over the Netherlands, implying that the average vertical wind speed profile is stable (Brand \& Hegberg, 2004).

Given the 10-minute average wind speed $\mu\left(z_{s}\right)$ and standard deviation $\sigma\left(z_{s}\right)$ at sensor height $z_{s}$, the estimates of the wind speed average and standard deviation at hub height $z_{h}$ are:

$$
\mu_{u, \text { esti }}\left(z_{h}\right)=\mu_{u}\left(z_{S}\right)+\sigma_{u}\left(z_{S}\right)\left(\ln \left(\frac{z_{h}}{z_{S}}\right)+5 \frac{z_{h}-z_{S}}{L_{\text {esti }}}\right)
$$

and

$$
\sigma_{\mathrm{u}, \mathrm{esti}}\left(\mathrm{z}_{\mathrm{h}}\right)=\sigma_{\mathrm{u}}\left(\mathrm{z}_{\mathrm{S}}\right)
$$

where $\mathrm{L}_{\text {esti }}$ is the location-dependent average Monin-Obukhov length.

If only $\mu\left(z_{s}\right)$ is available, and provided that the location is offshore, the estimates of the wind speed average and standard deviation at hub height are 


$$
\mu_{\mathrm{u}, \mathrm{esti}}\left(\mathrm{z}_{\mathrm{h}}\right)=\mu_{\mathrm{u}}\left(\mathrm{z}_{\mathrm{S}}\right)+2.5 \mathrm{u}_{*}\left(\ln \left(\frac{\mathrm{z}_{\mathrm{h}}}{\mathrm{z}_{\mathrm{S}}}\right)+5 \frac{\mathrm{z}_{\mathrm{h}}-\mathrm{z}_{\mathrm{S}}}{\mathrm{L}_{\text {esti }}}\right)
$$

and

where $\mathrm{u} *$ is determined from

$$
\sigma_{\text {u,esti }}\left(z_{h}\right)=2.5 u_{*}
$$

$$
\mu_{u}\left(z_{S}\right)-2.5 u_{*}\left(\ln \left(\frac{z_{S} g}{A u_{*}^{2}}\right)+5 \frac{z_{S}}{L_{\text {esti }}}\right)=0
$$

and $\mathrm{g}=9.81 \mathrm{~m} / \mathrm{s}^{2}$ is the gravitational acceleration and $\mathrm{A}=0.011$ is Charnock's constant.

\subsubsection{Averaging-time transformation}

A transformation from 10 to 15-minute averages is required by the design of the Dutch balancing market and is accomplished as follows: If $\mu_{\mathrm{k}}, \mu_{\mathrm{k}+1}, \mu_{\mathrm{k}+2}$ etc are the consecutive 10minute wind speed averages, then $m_{k} m_{k+1}$ etc. are the consecutive 15-minute wind speed averages:

$$
\mathrm{m}_{\mathrm{k}, \mathrm{esti}}=\frac{2 \mu_{3(\mathrm{k}-1) / 2+1}+\mu_{3(\mathrm{k}-1) / 2+2}}{3} \text { and } \mathrm{m}_{\mathrm{k}+1, \mathrm{esti}}=\frac{\mu_{3(\mathrm{k}-1) / 2+2}+2 \mu_{3(\mathrm{k}-1) / 2+3}}{3} \text {. }
$$

\subsubsection{Interpolation}

\subsection{4a Introduction}

This section describes how wind speed at given locations is sampled conditionally on the wind speed at measurement locations. To this end a multivariate Gaussian model is used, in combination with assumptions on the spatial and the temporal covariance structure. In addition, a variance-stabilizing transformation is used.

\subsection{4b Approach and assumptions}

Consider the natural logarithm $\mathrm{W}(\mathrm{x}, \mathrm{t})$ of the wind speed at a location $\mathrm{x}$ and time $\mathrm{t}$, where $t=(d, k)$ is defined by the day of the year $d$ and the time of day $k$. There are two reasons for taking the logarithm. First, there is a pronounced heteroscedasticity (i.e. increasing variance with the mean) in the wind speeds, which is stabilized by the log transformation (section 9.2 in Brockwell and Davis, 1991). Second, upon taking logarithms the (multivariate) normal case is reached, which allows one to make extensive use of conditioning.

Following Brockwell and Davis, 1991, a random vector $\underline{X}$ is considered which is distributed according to a multivariate normal distribution with mean vector $\underline{\mu}$ and covariance matrix $\underline{\underline{\Sigma}}$. Supposing that $\underline{X}$ is partitioned into two sub-vectors, where one corresponds to the sampled data and the other to the observed data, and, correspondingly, the mean vector and covariance matrix, then the following may be written:

$$
\underline{X}=\left(\begin{array}{l}
\underline{X}^{(1)} \\
\underline{X}^{(2)}
\end{array}\right) \text { and } \quad \underline{\mu}=\left(\begin{array}{l}
\underline{\mu}^{(1)} \\
\underline{\mu}^{(2)}
\end{array}\right) \text { with } \quad \underline{\Sigma}=\left(\begin{array}{ll}
\underline{\Sigma}_{11} & \underline{\Sigma}_{12} \\
\underline{\Sigma}_{21} & \underline{\Sigma}_{22}
\end{array}\right)
$$


If $\operatorname{det}\left(\Sigma_{22}\right)>0$, then the conditional distribution of $\underline{X}^{(1)}$ given $\underline{X}^{(2)}$ is again multivariate normal, and the conditional mean and the conditional covariance matrix are:

$$
\underline{\mu}^{(1)}+\underline{\Sigma}_{12} \underline{\Sigma}_{22}^{-1}\left(\underline{X}^{(2)}-\underline{\mu}^{(2)}\right) \text { and } \underline{\Sigma}_{11}-\underline{\Sigma}_{12} \underline{\Sigma}_{22}^{-1} \underline{\Sigma}_{21} .
$$

As to the log wind speeds $\mathrm{W}(\mathrm{x}, \mathrm{t})$ at location $\mathrm{x}$ and time $\mathrm{t}=(\mathrm{d}, \mathrm{k})$, the following model is proposed:

$$
W(x, t)=\mu(x, k)+\varepsilon(x, t),
$$

where $\mu$ is a deterministic function representing the daily wind pattern by location and $\varepsilon$ is a zero-mean random process representing the variations around the mean. Note that it has been assumed that $\mu$ depends on time only through the time of day $k$. In other words, the model does not include seasonal effects. (This assumption was checked and found to be reasonable in an analysis aimed at finding any other trend or periodic component, in particular a seasonal, in the 1-year data set.)

Figure 2 shows the average daily wind pattern for the 16 measurement locations. Since the lower curves correspond to onshore and the higher curves to offshore sites, the figure suggests that a daily effect is modeled which varies smoothly with geographical location. An onshore site is found to have a typical pattern with a maximum around midday, whereas an offshore site has a much flatter daily pattern, with a higher overall average. A coastal site falls in between.

The mean log wind speed $\mu(x, k)$ is estimated at all measurement locations by the daily averages shown in figure 2. Estimates for the locations of interest within the convex hull formed by the measurement sites were obtained by using linear spatial interpolation. On the other hand, for locations outside that hull, nearest neighbor interpolation was used. The results are shown as dotted lines in figure 2.

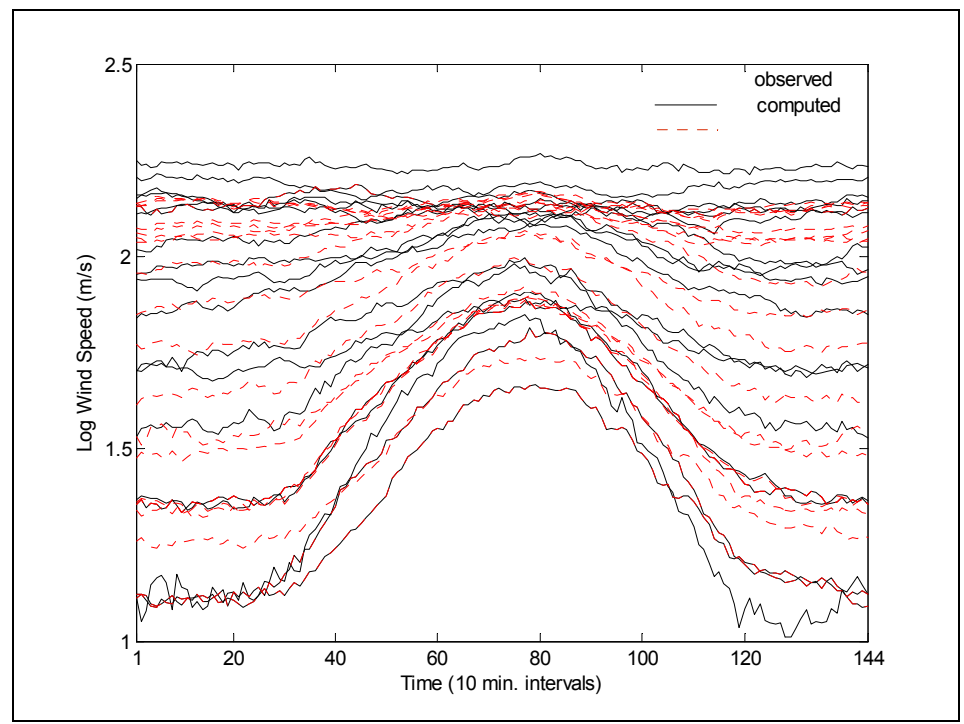

Fig. 2. Daily wind speed pattern for measured and interpolated sites 


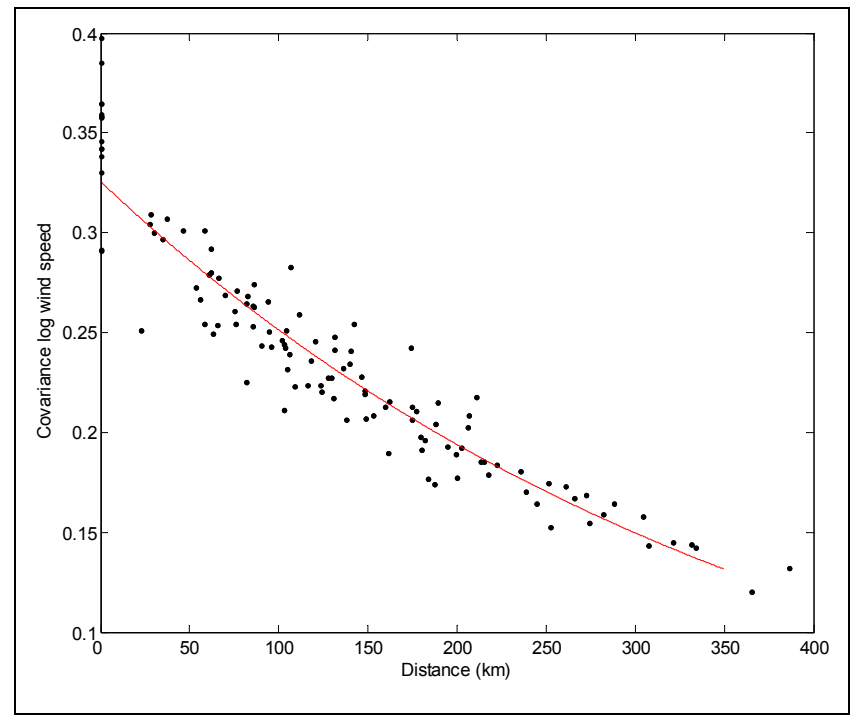

Fig. 3. Wind speed covariance versus site distance for 16 measurement sites

As to the model for the random part $\varepsilon(x, t)$, as explained above, a zero-mean, multivariate normal distribution is assumed for the log wind speeds minus the daily pattern. Figure 3 shows the sample covariance between the log wind speeds at all pairs of (measurement) locations versus the distance between them. From the displayed decay and the assumption that covariance vanishes at very large distances, it is reasonable to propose an exponential decay with distance:

$$
\operatorname{Cov}\left(\varepsilon\left(x_{i}, t\right), \varepsilon\left(x_{j}, t\right)\right)=a_{0} \exp \left(-\beta\left\|x_{i}-x_{j}\right\|\right)
$$

where $\|$.$\| denotes the Euclidean distance. To be able to sample wind speed time series,$ temporal dependence must be taken into account. Similar to equation (9), the following covariance is proposed:

$$
\operatorname{Cov}\left(\varepsilon\left(x_{i}, t\right), \varepsilon\left(x_{j}, t-1\right)\right)=a_{1} \exp \left(-\beta\left\|x_{i}-x_{j}\right\|\right)
$$

The parameters $a_{0}, a_{1}$ and $\beta$ are jointly estimated by a least squares fit. The fit for $a_{0}$ and $\beta$ is shown in figure 3 , where $\alpha=0.32$ and $1 / \beta=392.36 \mathrm{~km}$. The latter term is known as the characteristic distance. By transforming the parameters of this decay fit from logarithmic to pure wind speeds, and by inspecting the correlation coefficients (i.e. covariance normalized by the product of the two standard deviations) between location pairs, a value of $610 \mathrm{~km}$ is obtained for the characteristic distance. This value is in line with the $723 \mathrm{~km}$ reported in Chapter 6 of Giebel, 2000, which is based on measurements from 60 locations spread throughout the European Union, and the $500 \mathrm{~km}$ reported in Landberg et al., 1997, and Holttinen, 2005, using Danish only and Scandinavian data, respectively. This suggests that these values are generic. 
A final assumption is the Markov property for the sampled time series: it is assumed that conditionally on $W(x, t-1), W(x, t)$ does not depend on $W(x, t-2), W(x, t-3)$, etc. Consequently, it is not needed to specify the covariance between $W\left(x_{i}, t\right)$ and $W\left(x_{j}, s\right)$ when s-t $>1$.

It should be noted that since the equations 9 and 10 do not depend on time, any daily or seasonal changes in the covariance structure are ignored. Such effects have been tried to identify, but it was found that they were not very large, and not particularly systematic; hence, they would not have a substantial effect on the time series that the method ultimately generates.

\subsection{4c Interpolation scheme}

The interpolation scheme is as follows. At each stage, a collection of normal random variables is conditionally sampled on some other normal random variables. The mean and the covariance structure of all random variables is fully described, and therefore the general theory from equations 6 can be used, where subset (1) denotes the unobserved wind speeds at time $t$, and subset (2) denotes both observed wind speeds at times $t$ and $t-1$, and unobserved, but already interpolated values at time $\mathrm{t}-1$.

Once the log wind speeds for the locations of interest are sampled, these are exponentiated to obtain the wind speeds. Of course, the time series produced in this way will reflect the assumptions that were made, but this does not mean that they will look like samples from the multivariate log-normal distribution. The method provides nothing more than linear interpolations of the measured time series, and so their Weibull character will be preserved to a great extent.

The effectiveness of the method is evaluated by using cross-validation: leaving one measurement location out of the data set and using the remaining n- 1 locations to "re-create" it. First, it is verified that the method preserves the marginal Weibull parameters. As an illustration, figure 4 shows the histogram of the original data for the coastal location IJmuiden together with a Weibull fit of the original and the interpolated data. As expected, some smoothing has occurred in the interpolated data due to the weighted averaging, but not much. Second, it is verified whether or not the method reproduces the (auto-)covariance structure of the original data. Figure 5 shows the lag-one auto-correlations for the original and cross-validated data, with the straight line indicating a perfect match. Even though some over- and underestimation of the auto-covariances can be observed from figure 5, there does not seem to be any structural bias.

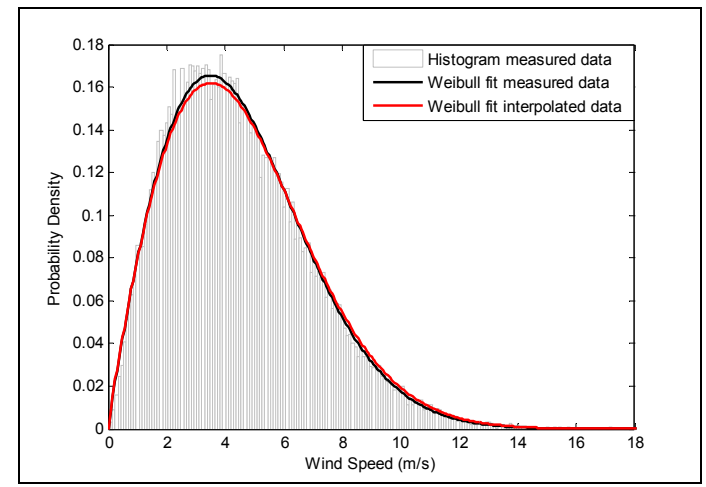

Fig. 4. Wind speed histogram and fit to Weibull distribution at the location IJmuiden 


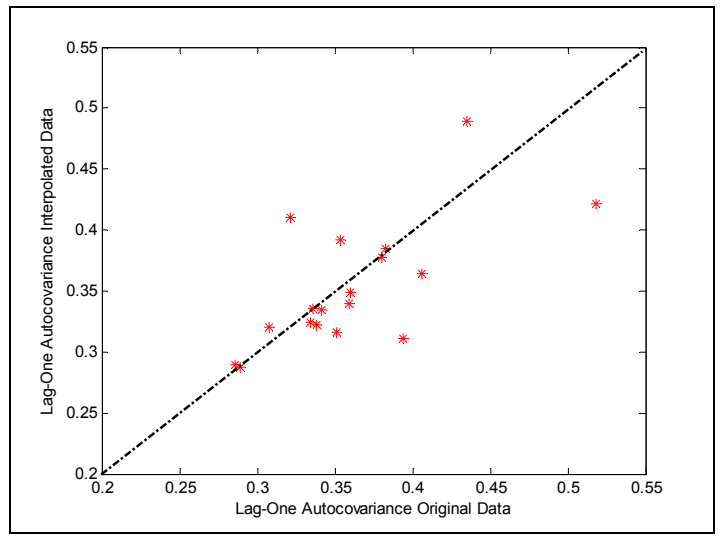

Fig. 5. Lag-one auto-covariance, original versus interpolated wind speeds

As to limitations of this method, it should be kept in mind that the interpolation weights are determined by the assumption of the exponential decay of the covariance with distance. As a consequence, if this decay does not hold, the covariance structure of the generated series will not be correct. In addition, the estimated time series are only as good as the input data allows. For instance, under more complex terrain, measured data at closer distances would be required to correctly track local changes in wind behavior.

\subsection{Forecasted wind speed}

The 15-minute average wind speed forecast time series are generated for locations where measurements are available. These forecasts originate from the wind power forecasting method AVDE (Brand and Kok, 2003); a physical forecasting method with an output statistics module. In an operational sense, AVDE is a post-processor to the high-resolution atmospheric model HiRLAM or any weather prediction model that delivers the required input data (two horizontal wind speed components, temperature and pressure in two vertical levels on a horizontal grid covering the sites to be considered) in the required format (GRIB). If wind speed and/or wind power realizations are available, the output statistics module of the AVDE can be used in order to compensate for systematic errors in the forecasts. The forecasts are meant to guide wind producers in a day-ahead market, and are completed at 12:00 the previous day, thus carrying an increasing delay of 12 to 36 hours. By employing a method similar to the one used for the spatial interpolation of wind speed measurements, appropriately correlated forecast error time series are generated for the wind farm locations. Since the variability of wind forecast errors over successive time intervals is not analyzed, it is assumed that, conditional on the forecast errors at the observed locations, the forecast errors at the computed locations at time $t$ are independent of the errors experienced at time $\mathrm{t}-1$.

Figure 6 presents the geographical locations of the seven wind speed forecast sites together with the projected offshore wind farm locations for the year 2020 and the current density of onshore wind energy capacity by province in the Netherlands.

Similar to the wind speeds, the forecast errors are modeled as the sum between a deterministic term, derived from the average daily pattern (figure 7), and a random term, which obeys a covariance matrix derived from the exponential fit presented in figure 8 . Note 


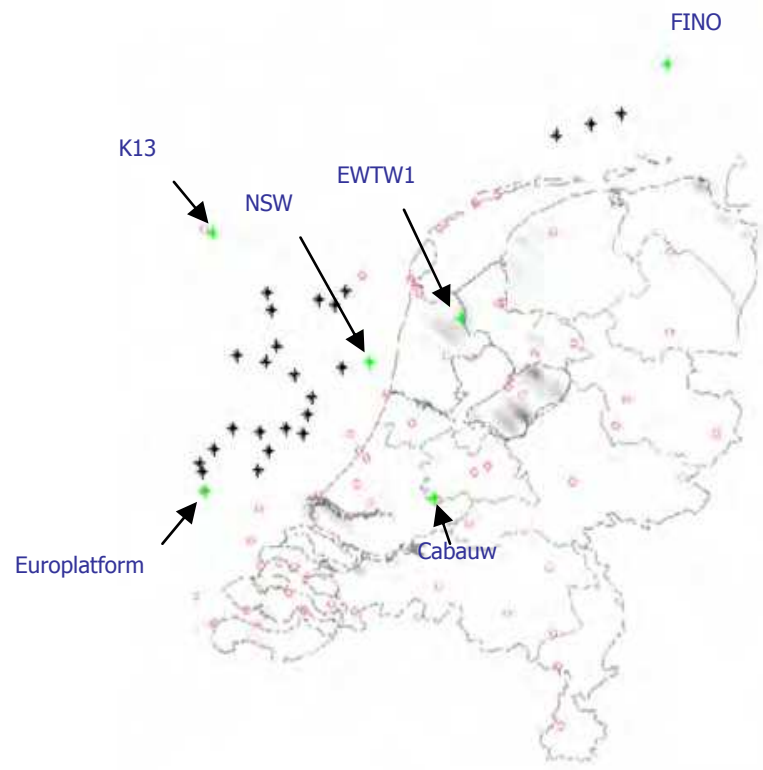

Fig. 6. Wind speed forecast sites (labeled), onshore (shaded grey) and offshore (black stars) wind farm sites for the Basic 2020 scenario

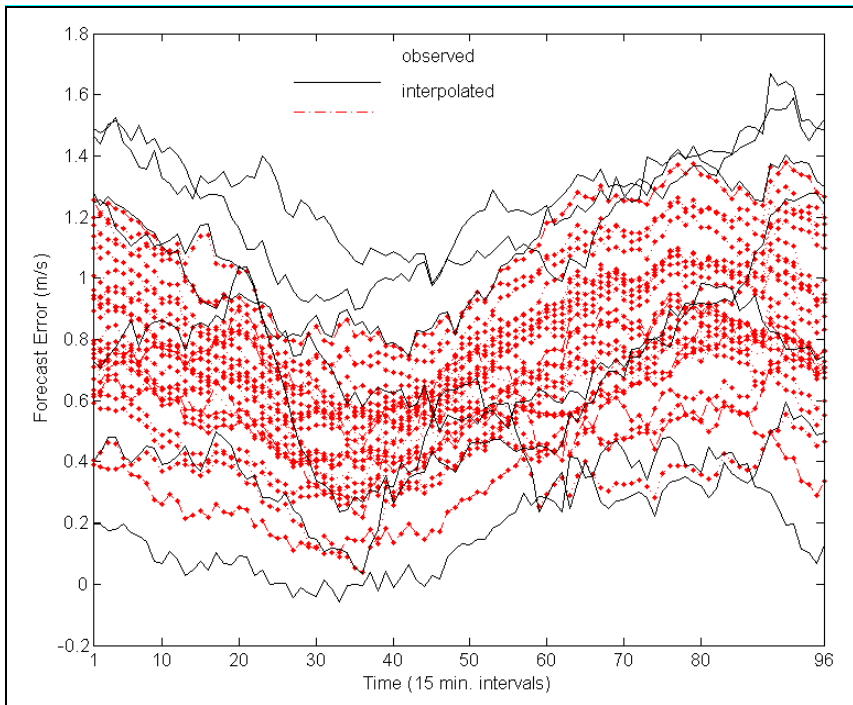

Fig. 7. Daily wind speed forecast error pattern for measured and interpolated sites 
that the logarithmic transformation was not necessary here because the variance of the forecasting error does not significantly increase with its mean. In order to correctly take into account the changes in the covariance structure due to the look-ahead time, $24 \times 4=96$ separate exponential decay curves were fitted as shown in figure 8.

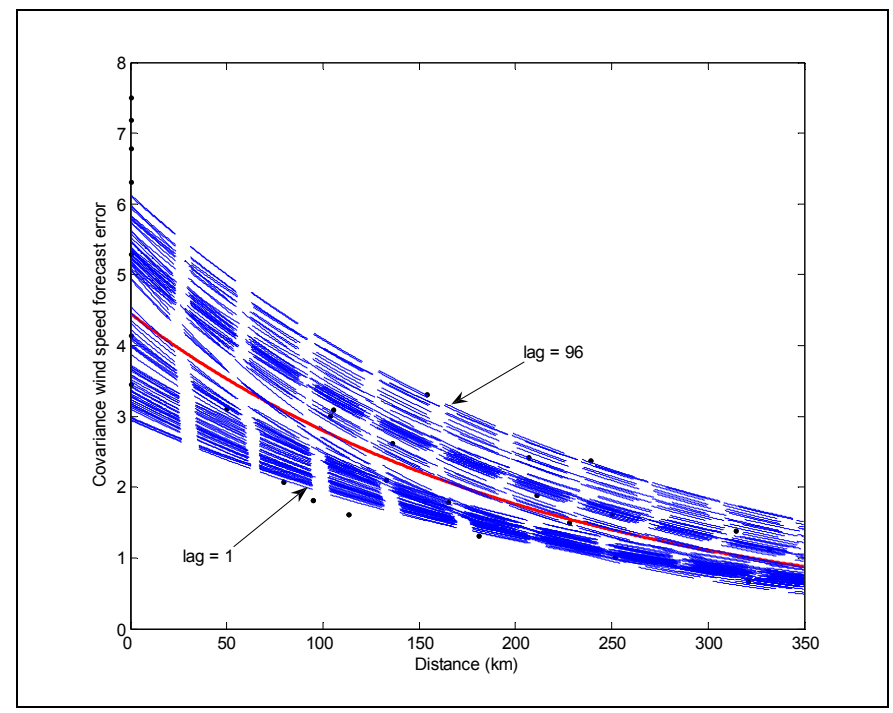

Fig. 8. Wind speed forecast error covariance versus distance for various forecast horizons

\subsection{Wind power}

\subsubsection{Multi-turbine power curve}

For each location wind power has been created using regionally averaged power curves, which depend on the area covered with wind turbines and the standard deviation of the wind speed distribution at the location. As the name suggests, regional averaging provides the average power of a set of wind turbines placed in an area where the wind climate is known, assuming the turbines do not affect each other. The multi-turbine curve is created by applying a Gaussian filter to a single-turbine power curve, and is not to be confused with a wind farm power curve, which brings the wind shadow of turbines into account.

Although inspired by and having the same effect as the Gaussian filter in the multi-turbine approach of Norgard and Holttinen, 2004, the standard deviation in the new filter correctly originates from the local wind climate alone. Unlike the Norgard-Holttinen method, the filter does not require estimating the turbulence intensity, which incidentally is a measure of variation in a 10-minute period in a given location rather than a measure of variation in the same 10-minute period at different locations. Nor does the method apply a moving block average to the wind speed time series with the time slot arbitrarily based on the local average wind speed.

Figure 9 shows an example of a multi-turbine power curve as constructed for an offshore wind farm of installed power $405 \mathrm{MW}$ at a location where the standard deviation of the wind speed is $4.6 \mathrm{~m} / \mathrm{s}$. The width $\sigma_{\mathrm{F}}$ of the Gaussian filter is given by an estimate for the standard deviation that describes the regional variation of wind speeds at different locations in the same wind climate (appendix A in Gibescu et al., 2009) 


$$
\sigma_{\mathrm{F}}=\sigma \sqrt{\frac{1}{2}\left(1-\exp \left(-\frac{\mathrm{d}_{\text {ave }}}{\mathrm{D}_{\text {decay }}}\right)\right)},
$$

where $\sigma$ is the standard deviation of the wind speed distribution, $d_{a v e}$ is the average distance between the locations and $\mathrm{D}_{\text {decay }}$ is the characteristic distance of the decay of correlation (as estimated in section 3). If the individual locations are not known, as is the case in this study, an estimate for $d_{\text {ave }}$ is (appendix B in Gibescu et al., 2009):

$$
\mathrm{d}_{\mathrm{ave}}=\frac{2}{3} \sqrt{\frac{\mathrm{A}}{\Pi}\left(1+\frac{2}{\sqrt{\mathrm{M}}}\right)},
$$

where $\mathrm{A}$ is the area of the region and $\mathrm{M}$ is the number of locations in that area. In this study, the area relates to a province for the onshore wind power and to an individual wind farm for the offshore wind power. The area of an individual farm is approximated by the area of a rectangle whose sides depend on the number of turbines, the rotor diameter and the spacing between turbines.

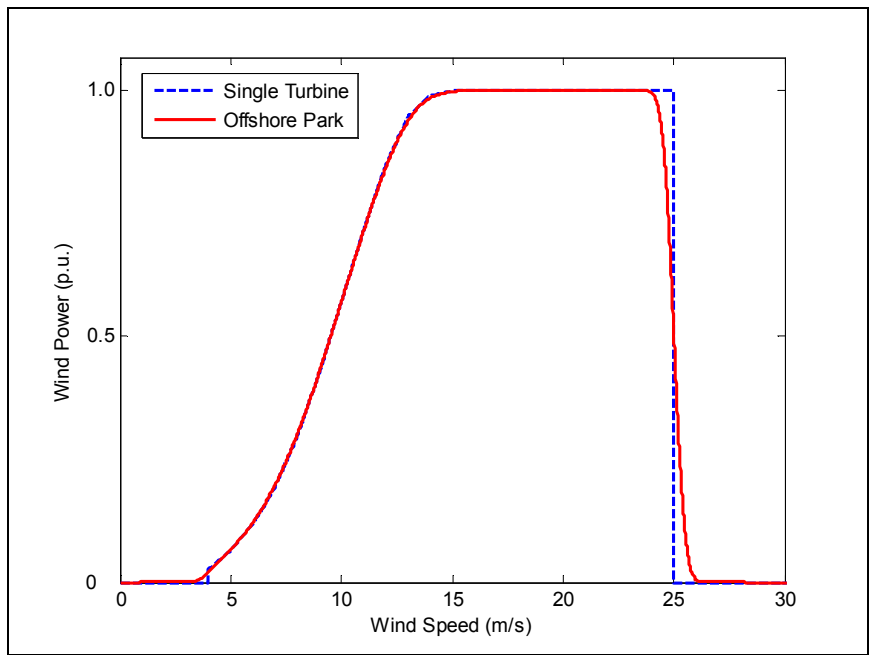

Fig. 9. Example of an aggregated power curve

The method to determine the regional variation of wind speeds at different locations in the same wind climate was verified by using the measured data introduced in section 4.3. The method to determine the multi-turbine power curve for a given area is still in need of verification data.

\subsubsection{Aggregation levels}

Aggregating the power of the individual wind farms at the system level gives a good initial estimate for the degree of variability and predictability that come with large-scale wind energy. It however ignores the real situation where wind power is integrated by several sublevels, as owned and operated by the individual market parties. To that effect, seven PRPs 
are defined, each owning a unique combination of installed power and geographical spread of onshore and offshore wind farms, as described in table 3. For reasons of confidentiality, these parties have fictitious names; however, the installed power are consistent with the current and planned developments in the Netherlands.

\begin{tabular}{|l|c|c|c|}
\hline PRP & Offshore (MW) & Onshore (MW) & Total (MW) \\
\hline Anton & 881 & 840 & 1721 \\
\hline Berta & 1792 & 593 & 2385 \\
\hline Cesar & 800 & 0 & 800 \\
\hline Dora & 2520 & 140 & 2660 \\
\hline Emil & 40 & 0 & 40 \\
\hline Friedrich & 0 & 92 & 92 \\
\hline Gustav & 0 & 135 & 135 \\
\hline System & 6033 & 1800 & 7833 \\
\hline
\end{tabular}

Table 3. Programme Responsible Parties (PRP) in the Basic 2020 scenario

\section{Impact of extra variability due to wind}

In this section the balancing energy requirements due to wind variability are presented for the scenario with 7.8 GW of installed wind power in the Netherlands in the year 2020.

Given the locations and installed power for future wind farms, the estimation method of the sections 4.3 and 4.4 is used in combination with the aggregated power curve of section 4.5 to compute the average wind power generated per 15-minute time interval for the duration of a year. By differentiating the wind power time series an estimate is obtained of the variability of aggregated power across 15-minute time intervals and above. This quantity and its sign are of interest because simultaneous load and wind variations are to be balanced by the remaining conventional generation units via the up- or down-ramping of their outputs.

Table 4 presents the $99.7 \%$ confidence intervals and the extreme values (smallest and largest) of the 15-minute, 30-minute, 1-hour and 6-hour variations at the system level. The sorted positive and negative variations in wind power over various time ranges are shown in figure 10 . Based on the $99.7 \%$ confidence interval, the system-wide variations across 15minute intervals are in the range of $\pm 14 \%$ of the installed power for this scenario.

Table 5 shows the statistics of the 15-minute variations for each of the seven PRPs individually. These variations are in the range of $\pm 12-26 \%$ of the power installed by the PRP, depending on the geographical spread of its locations. The collective requirement for balancing 15-minute variations becomes approximately $\pm 16 \%$ of the system's installed capacity, which is $2 \%$ more than the requirement at the system level.

\begin{tabular}{|l|c|c|c|}
\hline Time range & Minimum (MW) & Maximum (MW) & $99.7 \%$ Conf.Int. (MW) \\
\hline 15 min & -2411 & 2883 & -1090.8 to 1054.2 \\
\hline 30 min & -2411 & 2883 & -1252.9 to 1309.6 \\
\hline 1 hour & -3133 & 3634 & -1968.0 to 1846.0 \\
\hline 6 hour & -7211 & 6790 & -5157.8 to 5105.4 \\
\hline
\end{tabular}

Table 4. Statistics of wind variability in the Basic 2020 scenario 


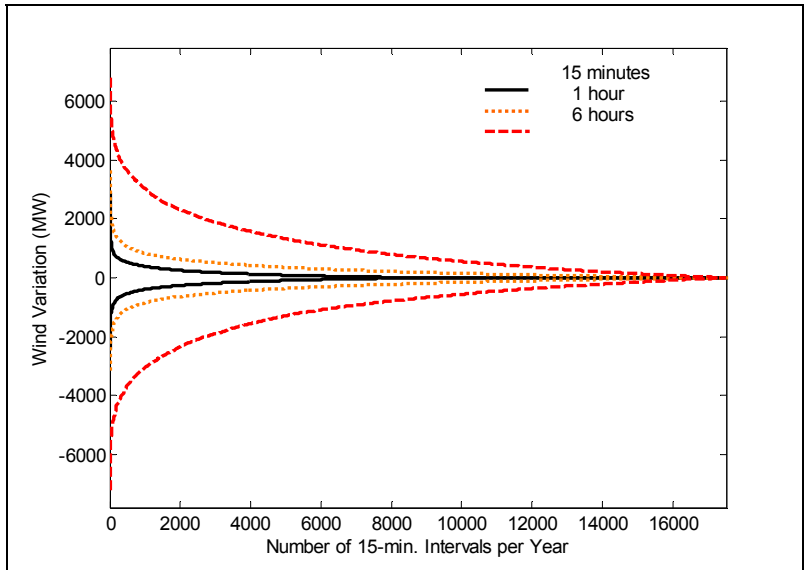

Fig. 10. Variations in $7830 \mathrm{MW}$ aggregated wind power

\begin{tabular}{|l|c|c|c|}
\hline PRP & Minimum (MW) & Maximum (MW) & 99.7\% Conf.Int. (MW) \\
\hline Anton & -367 & 481 & -201 to 197 \\
\hline Berta & -755 & 825 & -323 to 327 \\
\hline Cesar & -482 & 448 & -191 to 188 \\
\hline Dora & -1264 & 1420 & -461 to 484 \\
\hline Emil & -36 & 38 & -9 to 9 \\
\hline Friedrich & -48 & 42 & -22 to 24 \\
\hline Gustav & -74 & 78 & -26 to 27 \\
\hline Total PRPs & -3026 & 3332 & -1233 to 1256 \\
\hline System & -2411 & 2883 & -1091 to 1054 \\
\hline
\end{tabular}

Table 5. Statistics of 15-minute variability at the PRP level

\section{Impact of limited wind predictability}

In this section balancing energy requirements due to the limited predictability of wind are presented for the scenario with $7.8 \mathrm{GW}$ of installed wind power in the Netherlands in the year 2020.

To this end a statistical analysis is performed of the forecasting error as aggregated over the wind production of the Netherlands. The time series of forecasted 15-minute average wind power include different day-ahead forecasts issued at 24, 18, 12 and 6 hours before delivery. System reserve is allocated among online generators to account for equipment outages and uncertainties in load and wind forecast errors. Obviously the higher the forecast uncertainty, the larger the amount of reserve needed to achieve the same reliability level. Figure 11 shows the normalized histogram for the system-aggregated forecast error, together with the fit to a double-exponential probability density function, which was found to be a more accurate analytical representation of the data than the normal distribution.

Table 6 shows the predictability at the system level in terms of the $99.7 \%$ confidence interval plus the average, standard deviation, minimum and maximum of the imbalance. (Imbalance 
is equal to wind power forecast error.) Statistics for positive and negative imbalance are presented in the second and third rows of table 6, respectively. Based on the $99.7 \%$ confidence interval, the positive (up-regulation or reserve) balancing energy requirement is about $56 \%$, and the negative (down-regulation) requirement is about $53 \%$ of the installed capacity.

Table 7 shows the predictability at the PRP level. Balancing energy requirements for an individual PRP are in the range $45-82 \%$ of its installed capacity for up-regulation or reserve, and $46-72 \%$ for down-regulation.

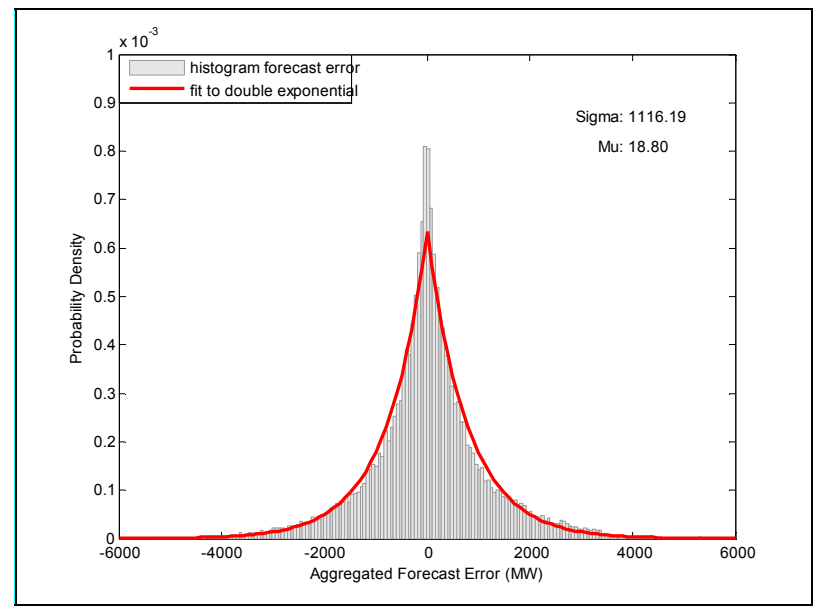

Fig. 11. Aggregated forecast error histogram and probability density function for $7830 \mathrm{MW}$ installed wind power

\begin{tabular}{|l|c|c|c|r|c|}
\hline Imbalance (MW) & Minimum & Maximum & 99.7\% Conf.Int. & \multicolumn{1}{c|}{ Mean } & St.Dev. \\
\hline Total & -5366 & 5692 & -4112.9 to 4370.6 & 18.8 & 1116.2 \\
\hline Positive & 0 & 5692 & 1.2 to 4765.2 & 789.8 & 821.1 \\
\hline Negative & -5366 & 0 & -4471.8 to -1.0 & -754.7 & 790.5 \\
\hline
\end{tabular}

Table 6. Statistics of wind predictability at the system level

\begin{tabular}{|l|c|c|c|}
\hline PRP & Minimum (MW) & Maximum (MW) & $99.7 \%$ Conf.Int. (MW) \\
\hline Anton & -1057 & 1156 & -787 to 773 \\
\hline Berta & -1604 & 1621 & -1239 to 1242 \\
\hline Cesar & -696 & 798 & -575 to 660 \\
\hline Dora & -1941 & 2169 & -1577 to 1726 \\
\hline Emil & -35 & 39 & -26 to 26 \\
\hline Friedrich & -78 & 67 & -56 to 45 \\
\hline Gustav & -116 & 109 & -85 to 74 \\
\hline Total PRPs & -5527 & 5959 & -4345 to 4546 \\
\hline System & -5366 & 5692 & -4113 to 4371 \\
\hline
\end{tabular}

Table 7. Statistics of predictability at the PRP level 
The collective requirement is about $58 \%$ of the total capacity for up-regulation or reserve, and about $56 \%$ for down-regulation. These collective requirements are larger by up to $3 \%$ than if the balancing actions were taken at the system level.

In addition, a statistical analysis is performed of the power forecast error by look-ahead time, which in this case varies between 48 and 144 PTUs (i.e. 15-minute intervals), or 12-36 hour. The results are shown in figure 12, expressed in percentage with respect to the installed power. As expected, the performance of the forecast degrades slightly with lookahead time. The best values obtained are for the 12-hour-ahead forecast, where the standard deviation is $12.7 \%$, and the $99.7 \%$ confidence interval is [ $-50 \%$ to $+48 \%]$. The standard deviation for the 36 -hour-ahead forecast goes up to $17.2 \%$.

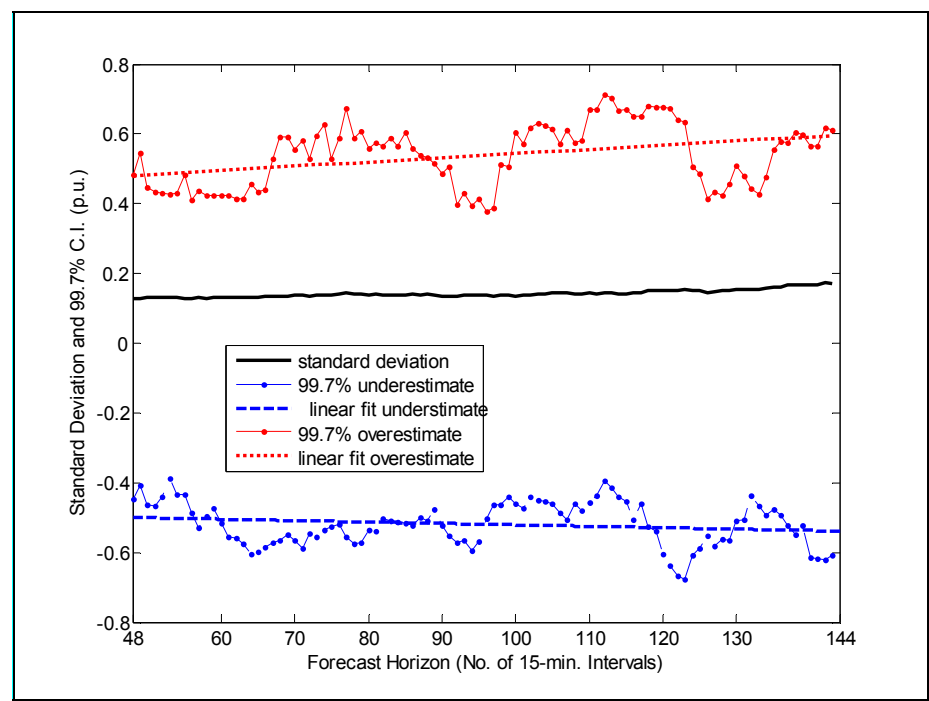

Fig. 12. Standard deviation and $99.7 \%$ confidence interval of the aggregated forecast error by forecast horizon

\begin{tabular}{|l|c|c|c|}
\hline & MW & $P_{\text {average }}(\%)$ & $P_{\text {installed }}(\%)$ \\
\hline RMSE & 1116.2 & 32.8 & 14.2 \\
\hline MAE & 772.3 & 22.7 & 9.8 \\
\hline
\end{tabular}

Table 8 . Overall predictability statistics for $7830 \mathrm{MW}$ of wind power

Table 8 presents the overall forecast error measures: the root mean square error (RMSE) and the mean absolute error (MAE); see Madsen et al., 2005. The values are presented both in absolute and in percentage with respect to the average power and with respect to the nominal power. The percent RMSE value of $14.2 \%$ for the system level is smaller compared with the $17-19 \%$ for the single wind farm level, and the percent MAE (9.8\%) is also smaller compared with the 12-14\%, both reported in Madsen et al., 2005, in percent of installed power for lead times between 12 and 36 hour. The values calculated in percentage with respect to the average power (equal to $3434.5 \mathrm{MW}$ for the $7800 \mathrm{MW}$ installed capacity scenario) are understandably higher. Note that in the presence of an intra-day market, the aggregated forecast errors could drop to about half of the day-ahead values, as simulated in Ummels et al., 2007. 


\section{Instruments for balancing wind energy}

\subsection{Outline}

This section contains a critical discussion on options to reduce the extra balancing energy requirements for the scenario with $7.8 \mathrm{GW}$ of installed wind power in the Netherlands in the year 2020. The following instruments for balancing wind power forecasting errors are analyzed: short-term forecast updates and aggregation (section 7.2), pumped storage, compressed air storage and fast start-up units (section 7.3), and inverse pumped accumulation (section 7.4). In addition, a wind farm shut-down strategy is discussed in section 7.5.

\subsection{Short-term forecast updates and aggregation}

\subsubsection{Influence of forecast lag on system imbalance}

The accuracy of wind power forecasts is evaluated by comparing the forecasted values to the produced amounts. The key indicator is the capacity normalised mean of the absolute forecast error (cNMAE) (Madsen et al., 2005). As table 9 shows, the impact of bad day-ahead forecasts can be alleviated by making use of forecast updates. This clearly shows the importance of continuous wind power forecast updates, which will also allow for a better allocation of the forecast errors within the operation of other generation units in the system.

\begin{tabular}{|l|r|l|}
\hline Forecast lag before delivery & \multicolumn{2}{|c|}{ cNMAE [\%] } \\
\hline & Min & Max \\
\hline 24 hours & 10.5 & 13.5 \\
\hline 18 hours & 10.0 & 13.0 \\
\hline 12 hours & 9.0 & 11.5 \\
\hline 6 hours & 8.5 & 11.5 \\
\hline
\end{tabular}

Table 9. Capacity normalized mean absolute forecast error (cNMAE) for different day-ahead forecasts (Duguet and Coelingh, 2006)

Another indicator for the forecast accuracy is the capacity normalized standard deviation of the wind power forecast error (cNRMSE). As shown in figure 13, the cNRMSE is found to drop to half between the forecasts performed at 36 hours and 3 hours before delivery.

It should however be noted that neither the NMAE nor the NRMSE of forecasts based on numerical weather prediction models reduce to zero if the forecast lag approaches present time because of the intrinsic uncertainty in these models. Such a reduction however can be achieved if online production data is included in the forecasts, as is done in figure 13, also showing the cNRMSE for the 0 to 6 hours before delivery.

\subsubsection{Aggregation of forecast errors at different levels}

The impact of aggregation of wind power on imbalance due to wind power forecast errors is investigated on the basis of forecasts issued 24 hours before the day of delivery. Two aggregation levels are considered: the system level and the Programme Responsible Party (PRP) level. The PRP level consists of seven individual market parties, each with some wind power as part of their portfolio; see table 3. The hypothesis is that a central aggregation would allow internal cancelling out of forecast errors. It is found that this indeed is the case: aggregation at the system level requires about $6 \%$ less overall reserves for the compensation of forecast errors (this is the percent reduction in the length of the confidence interval, as computed from table 10). 


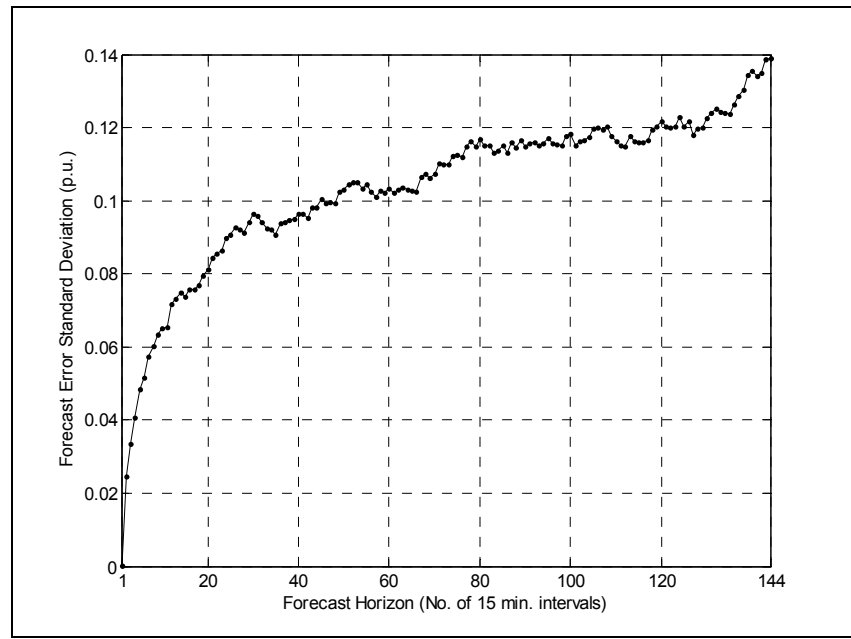

Fig. 13. Capacity normalized standard deviation (cNRMSE) of the wind power forecast error for $7800 \mathrm{MW}$ of wind power

\begin{tabular}{|l|c|c|c|}
\hline & \multicolumn{3}{|c|}{ Wind power forecast error } \\
\hline & $\begin{array}{c}\text { Max. } \\
{[\mathrm{MW}]}\end{array}$ & $\begin{array}{c}\text { Min. } \\
{[\mathrm{MW}]}\end{array}$ & $\begin{array}{c}99.7 \% \text { Conf.Int. } \\
{[\mathrm{MW}]}\end{array}$ \\
\hline Sum PRPs & +5257 & -5450 & {$[-3754 \ldots 4071]$} \\
\hline System & +5148 & -5326 & {$[-3482 \ldots 3907]$} \\
\hline Difference & 109 & -124 & {$[-272 \ldots$ 164] } \\
\hline
\end{tabular}

Table 10. Range and confidence interval of wind power forecast error for the sum of individual PRPs and the system

\subsection{Pumped storage, compressed air energy storage and fast start-up units}

\subsubsection{Methodology}

In this section, pumped storage and compressed air technologies of similar energy content are compared. It is assumed that the storage system does not participate in any market trading, in order to focus on the effectiveness of various technologies in reducing imbalances arising from wind speed forecasting errors. As a further simplifying assumption, the storage system is allowed to reverse operation between consecutive Programme Time Units (PTU), i.e. from charging to discharging and vice versa, depending on the sign of the forecast error.

The following comparably-sized storage systems are analyzed for the scenario with 7800 MW installed wind power, and a 24-36 hour lead time for the wind forecasts:

- A pumped storage (PS) system of $10.08 \mathrm{GWh}$, charging time 8 hours, hence $1260 \mathrm{MW}$ installed power, with a 0.81 round-trip efficiency, i.e. equal 0.9 pumping and generating efficiencies, with efficiencies independent of charging levels.

- A compressed air energy storage (CAES) system of 7.2 GWh, charging time 8 hours, with a 0.8 compression efficiency and a 1.4 charge efficiency factor, which means that the amount of energy that can be generated at full discharge is $7200 \times 1.4=10.08 \mathrm{GWh}$, thus equal to the pumped storage. 
In addition, the effect of $852 \mathrm{MW}$ of installed fast start-up units on the reduction of negative imbalances (less wind power than predicted) is analyzed. Negative imbalances are considered more dangerous to system reliability than positive ones, which can ultimately be taken care of by curtailing excess wind production. The fast start-up units are supposed to complement the pumped storage and so the value of $852 \mathrm{MW}$ was chosen as equal to the standard deviation of the imbalance remaining in the system after the implementation of the $10.08 \mathrm{GWh}$ pumped storage system. It is assumed that the fast start-up power can be switched on or off in increments of $2 \mathrm{MW}$, and reacts to correct imbalances whose absolute value is bigger than $200 \mathrm{MW}$. This prevents an unnecessarily large number of start-ups and shut-downs in cases when the imbalance is less than $200 \mathrm{MW}$ and can thus be covered from the spinning reserve carried by conventional units on-line. It is assumed that the fast startup units are open-cycle gas turbines (OCGT), and hence are capable of starting and ramping up to their installed capacity within one PTU, i.e. 15-minute time interval.

\subsubsection{System level aggregation}

As an illustration, figure 14 shows a 52-day (5000 PTUs) sample from the yearly time series for the original and the reduced imbalance after the application of a $10.08 \mathrm{GWh}$ pumped storage system in combination with $852 \mathrm{MW}$ installed capacity from fast start-up units.

Results from the comparison of the various technologies are summarized in table 11, which shows the reduced standard deviation and the average positive and negative imbalances, all in terms of per unit with respect to their original values.
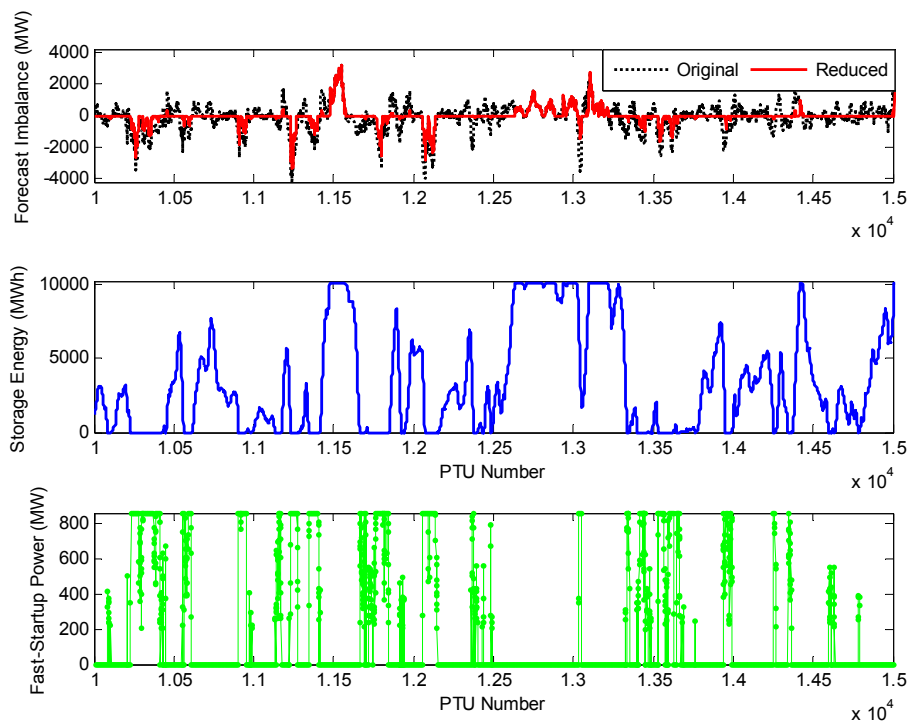

Fig. 14. Time series for 52 days of forecast imbalance, state-of-charge and fast start-up power with a $10 \mathrm{GWh}$ pumped storage system and $852 \mathrm{MW}$ of open-cycle gas turbines

In addition, the reduced $99.7 \%$ confidence intervals for the aggregated forecast error are shown in the last row. As a reference point, the original confidence interval before applying any storage was [-3948 ... 3441] MW. 


\begin{tabular}{|c|c|c|c|}
\hline & $\begin{array}{c}\text { 10080 MWh } \\
\text { Pumped Storage }\end{array}$ & $\begin{array}{c}\text { 7200 MWh } \\
\text { CAES }\end{array}$ & $\begin{array}{c}\text { 10080 MWh PS } \\
\text { 852 MW Fast Start-Up }\end{array}$ \\
\hline$\sigma$ [p.u.] & 0.84 & 0.84 & 0.66 \\
\hline$\mu^{+}$[p.u.] & 0.61 & 0.68 & 0.61 \\
\hline$\mu^{-}$[p.u.] & 0.68 & 0.64 & 0.25 \\
\hline $99.7 \%$ C.I. $[\mathrm{MW}]$ & {$[-3530 . .3310]$} & {$[-3421 . .3326]$} & {$[-2678 . .3310]$} \\
\hline
\end{tabular}

Table 11. Statistical properties for the system imbalance reduction

From table 11 it can be seen that it is easier for the pumped storage system to take care of positive (excess wind) imbalances. This is because the 0.9 pumping and generating efficiencies lead to consuming $111 \%$ more energy than stored from the positive (excess wind) forecasting errors, whereas only $90 \%$ of the stored energy can effectively be used when discharging to cover for negative (deficit wind) errors. The overall standard deviation has been reduced by the CAES system to the same value as in the case of the PS system, i.e. $84 \%$ (from 1013 to $852 \mathrm{MW}$ ). By contrast, the CAES system, thanks to its charge efficiency factor of 1.4, is slightly better at taking care of negative imbalances than a PS system of comparable installed capacity. However, unlike PS, a CAES "discharge" implies burning of fuel (gas) and hence extra emissions and higher operating costs.

The technology for diabatic CAES systems is available and already has been applied successfully, e.g. the Huntorf plant in Germany, already in operation for about 20 years. In the Netherlands there are a small number of caverns (unused salt domes) which can be used for CAES. However these caverns are more favorable for storing gas or $\mathrm{CO}_{2}$. For this reason it is concluded that CAES development in the Netherlands will be hard and will have to compete with other technologies.

The last column of table 11 shows the results for the pumped storage and fast start-up units combination. The resulting reduction in average negative imbalance is to $25 \%$ of its original value, which is achieved with an average of 6.5 start-ups per day. The reduction in positive imbalance is naturally the same as that without the fast start-up units, whereas the overall standard deviation is now reduced to $66 \%$ (667 MW).

\subsubsection{PRP level aggregation}

The installed $7800 \mathrm{MW}$ wind power is now distributed over seven market parties at the Programme Responsible Party (PRP) level; see table 3. In order to facilitate comparison with the results for the system level aggregation, the installed storage and fast start-up capacities are allocated proportionally to the installed wind power of each PRP. These installations are now controlled to correct the individual imbalances due to forecasting errors as experienced by each PRP. Figure 15 shows the reductions in negative imbalance for system versus PRP level aggregation, for various technologies, and increasing values of storage capacities, up to $30 \mathrm{GWh}$. From this figure it can be noted that installing storage and/or fast start-up units to be controlled for reducing the imbalance at system level is slightly more advantageous than at the PRP level in terms of reducing the average negative imbalance. The advantage stays approximately constant regardless of storage capacity, with the largest difference experienced for the PS and fast start-up combination, at about 0.12 p.u., which translates to $86 \mathrm{MW}$. By contrast, installing storage and fast start-up units to be controlled for reducing the imbalance at PRP level is slightly more advantageous than at the system level in terms of reducing the total spread -- or standard deviation -- of the imbalance. The advantage 
increases with higher storage capacities, with the largest difference being about 0.025 p.u., which translates to about $25 \mathrm{MW}$.

It is concluded that differences between system and market participant level aggregation seem insignificant from the standpoint of being more or less effective in reducing the forecast imbalance. It follows that decisions about where storage units are to be installed and how they are to be controlled will probably be governed more by geographical constraints, considerations about economies of scale, ease of accounting, technical accessibility and confidentiality of control signals.

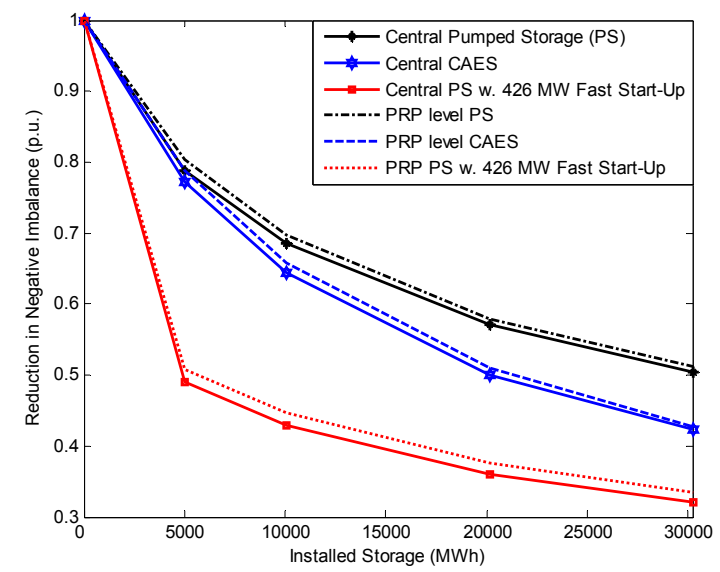

Fig. 15. Reductions in average negative imbalance for PS, CAES and PS with $426 \mathrm{MW}$ fast start-up units for PRP versus system level aggregation

\subsection{Inverse offshore pump accumulation system}

Next an inverse offshore pump accumulation system (IOPAC) is considered (de Boer et al., 2007). The IOPAC has been proposed to be stationed on an "Energy Island", that is an artificial island at sea consisting of a ring of dikes $\left(6 \times 10 \mathrm{~km}^{2}\right)$ enclosing a deep dredged reservoir. The intended depth of the reservoir is $50 \mathrm{~m}$ below sea level, and the water level of the reservoir will typically vary between -32 and $-40 \mathrm{~m}$. In figure 16 an artist impression of the "Energy Island" is shown.

The IOPAC is equipped with a control system that aims to prevent the storage from being saturated, and thus makes it more capable of reducing the imbalance due to wind energy. The strategy of the control system involves selling power during peak hours ( 8 am to $11 \mathrm{pm}$ ) if the water level is too low, and buying power during off-peak hours if the water level is too high. In this way the control system keeps the water level around the half-full operating point (around $-36 \mathrm{~m}$ ).

Energy is bought from or sold to the intra-day market, assuming any needed energy volume is available within the limits of the storage device. This is feasible; whether a surplus or a shortage of energy in the reservoir can be noticed by simply monitoring the water level. The lower part of figure 17 shows this correction signal (where positive power means bought from the market and used to charge the storage system). 


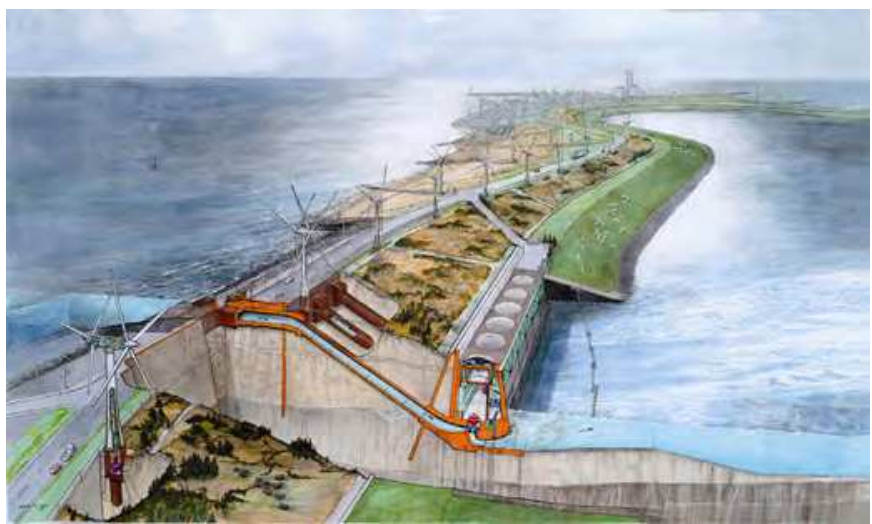

Fig. 16. Artist impression of the Energy Island with an Inverse Offshore Pump Accumulation (IOPAC)
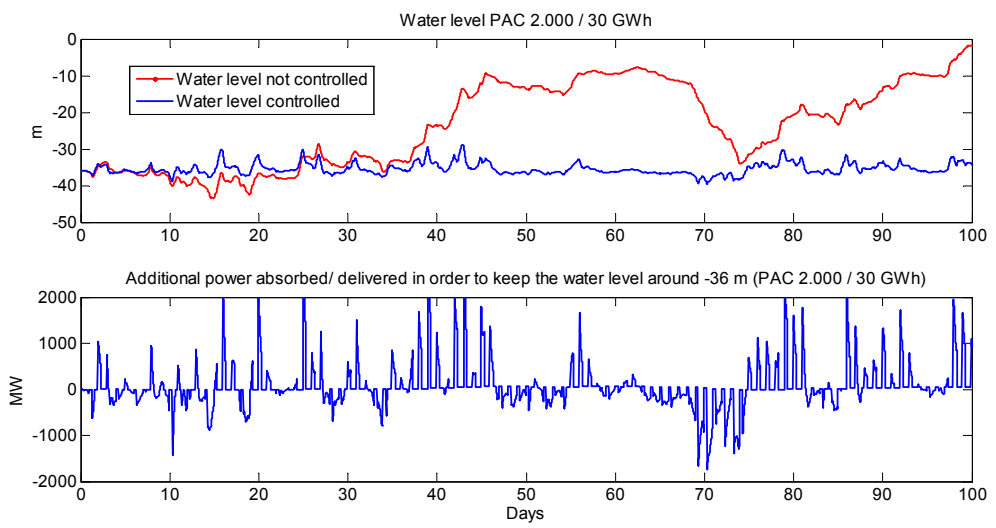

Fig. 17. Impression of average power absorbed/delivered in order to maneuver the IOPAC around the half-full operating point

The effectiveness of the IOPAC in alleviating imbalance is analyzed by considering a pump/turbine power rating of $2000 \mathrm{MW}$, with a storage energy capacity of $30 \mathrm{GWh}$. Initial imbalances result from wind power forecasts issued at noon before the day of delivery (with a lag of 12-36 hours). The upper part of figure 17, showing the impact of the control system on the variation of the water level as a response to these imbalances, reveals that the control system prevents the water level from drifting away. Figure 18 shows the original imbalance, the imbalance after employing the IOPAC alone, and the imbalance for the IOPAC with intelligent control strategy. The imbalance reduction, measured in terms of per unit standard deviation with respect to the base-case, ranges from 0.714 (IOPAC alone) to 0.697 (IOPAC with intelligent control). Some imbalance remains after the application of IOPAC, but this could be handled by fast responding conventional units and/or combining these measures with short-term wind power forecasts.

The proposed intelligent IOPAC is therefore shown to alleviate imbalances due to wind power forecast errors. 

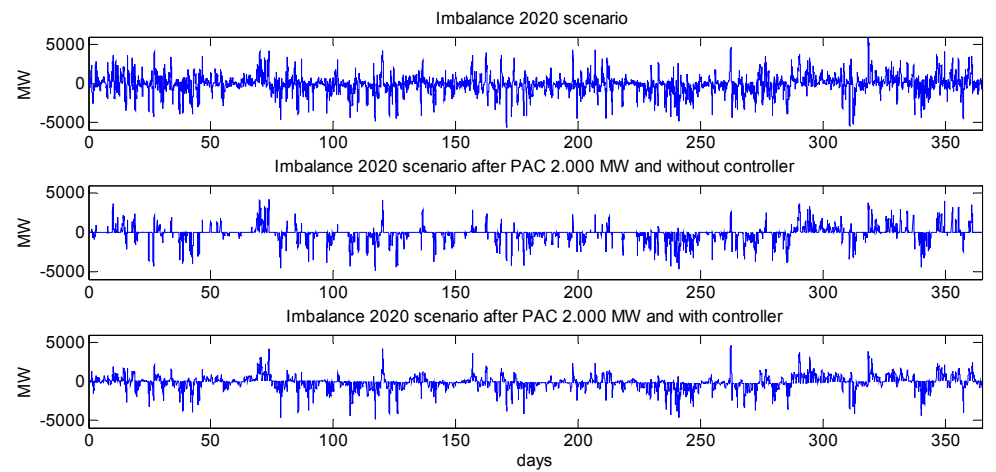

Fig. 18. Imbalance before and after the application of IOPAC storage, $2000 \mathrm{MW}$ installed power, with $30 \mathrm{GWh}$ energy capacity

\subsection{Wind farm shut-down strategies}

Finally, the impact of wind farm shut-down strategy on the imbalance is analyzed. Two shut-down strategies are considered. In the abrupt shut-down strategy, a wind farm is shut down within 10 seconds if the 15-minute averaged wind speed exceeds $25 \mathrm{~m} / \mathrm{s}$, and is started up again within 10 seconds if the 15-minute average wind speed is less then $22 \mathrm{~m} / \mathrm{s}$. In the gradual shutting-down strategy, on the other hand, the power of a wind farm varies linearly with the wind speed between full load and zero if the 15-minute averaged wind speed is between 23 and $32 \mathrm{~m} / \mathrm{s}$.

In practice the abrupt shut-down strategy or a close variant is applied, where the turbines in a wind farm may either shut down individually based on their individual wind speed measurements or collectively based on one central wind speed measurement system in the wind farm. In this analysis a whole wind farm shuts down based on its 15-minute averaged wind speed. Also, in reality the shutting-down and starting-up times may differ from the value of $10 \mathrm{~s}$ employed in this analysis. These choices however do not strongly affect the conclusions.

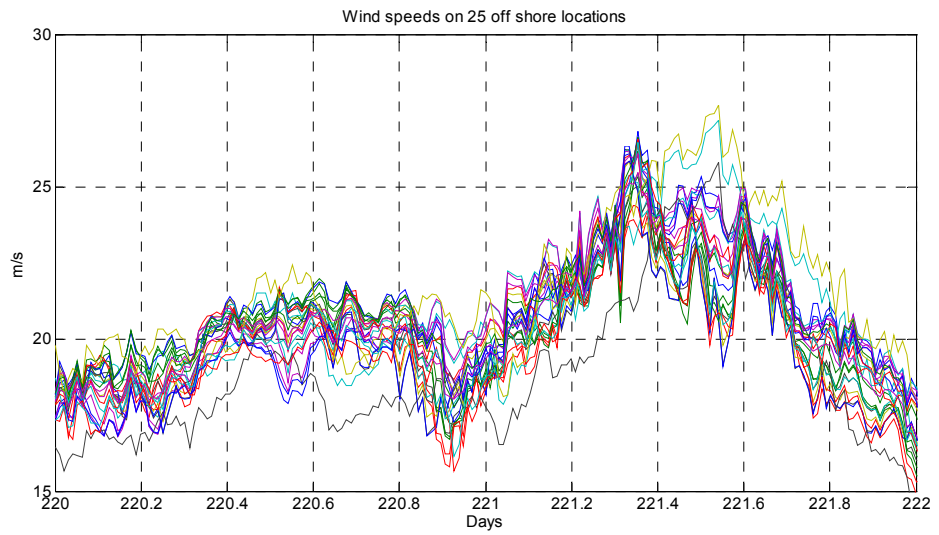

Fig. 19. The wind speed at the 25 offshore locations during one day with wind speeds exceeding $25 \mathrm{~m} / \mathrm{s}$ 
In addition the 15-minute average wind speeds at the wind farm locations foreseen in the Netherlands for the period of one year were considered. It is found that on three days the wind speed exceeds $25 \mathrm{~m} / \mathrm{s}$ in at least one location. Day 222 was selected for further analysis; the wind speeds are presented in figure 19. It should be noted that the wind speed does not exceed $25 \mathrm{~m} / \mathrm{s}$ at all wind farms, so that not all wind farms shut down.

As shown in figures 20 and 21, with the abrupt shut-down strategy, there are large differences between the forecasted and the produced wind power, and, as a consequence, larger imbalances. With the gradual shut-down strategy, the differences are significantly less. It was found that with gradual shut-down the imbalance due to forecasting errors is reduced by more than $50 \%$ as compared to abrupt shut-down. In addition, benefits in terms of decreasing the variability in the wind power output can also be observed in figure 20.

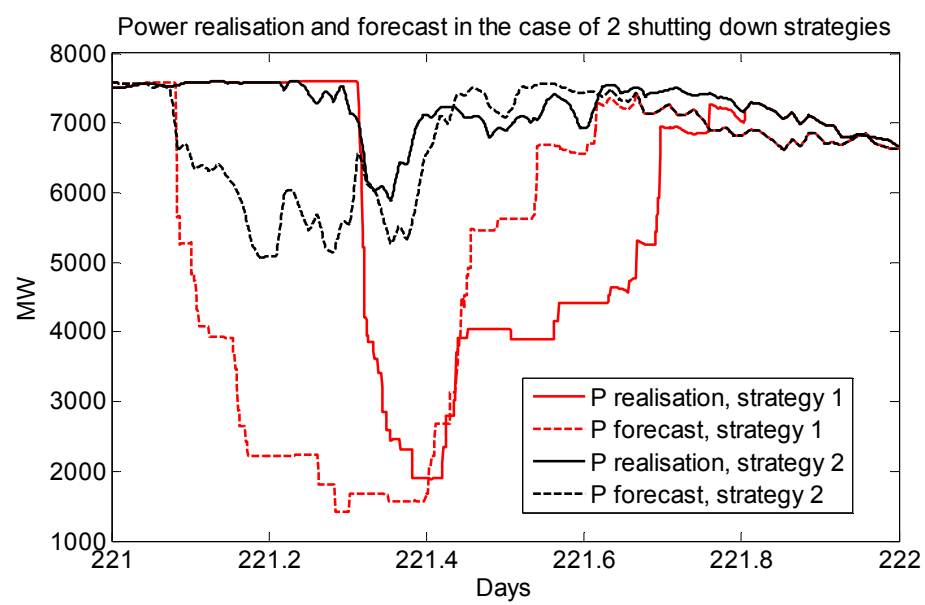

Fig. 20. Wind power production and forecast during the day with wind speeds over $25 \mathrm{~m} / \mathrm{s}$ and after applying the abrupt and gradual shut-down strategies

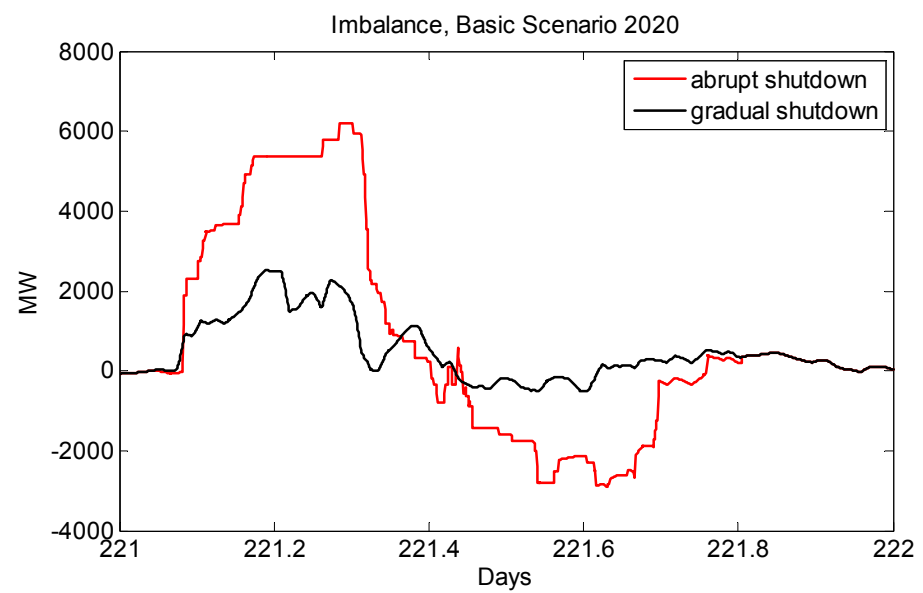

Fig. 21. Remaining forecast imbalance during the day with wind speeds over $25 \mathrm{~m} / \mathrm{s}$ and after applying the abrupt and gradual shut-down strategies 
The concept of shutting down the wind farm gradually as a linear function of the (high) wind speed is therefore found to be significantly better than abrupt shut-down.

\section{Summary}

A statistical interpolation method to generate time series of system- and participantaggregated wind power production and forecast values has been presented. The method takes into account the spatial and temporal correlations among multiple sites, as derived from the measurement and forecast data. In addition, a method for deriving parkaggregated power curves with smooth cut-in and cut-out, that takes into account the local wind climate, was introduced.

In the scenario with 7.8 GW of wind power in the Netherlands in the year 2020, at the system level the imbalance energy requirements due to wind variations across 15-minute intervals are $\pm 14 \%$, while the imbalance energy requirements due to forecast errors vary between $53 \%$ down-regulation and $56 \%$ up-regulation or reserve. If 15-minute variations and forecast errors are compensated individually by market participants, the collective balancing energy requirements are larger: $\pm 16 \%$ for the 15 -minute wind variations, and between $56 \%$ down-regulation to $58 \%$ up-regulation or reserve for the forecast errors.

Various alternatives for balance control as required by the addition of wind energy in the Netherlands have been investigated. From this analysis it is concluded that the following instruments for balance control are most applicable: continuously updated short-term forecasts, pumped-accumulation storage systems, fast start-up units, and gradual shutdown strategies for wind farms.

\section{Acknowledgements}

This work was funded by the Dutch Ministry of Economic Affairs partly under the EOS-LT project "RegelDuurzaam" and partly under the BSIK programme We@Sea, project "Systeemintegratie en balanshandhaving". The measured wind data originate from KNMI, ECN and DEWI. The HiRLAM data originate from KNMI. The authors would like to thank the project partners from Ecofys, TenneT and KEMA for their valuable comments. The authors like to thank Jan Coelingh from Ecofys for providing the data in table 9.

\section{References}

de Boer W.W., Brand A.J. \& Gibescu M. (2007), System balancing with 6 GW offshore wind energy in the Netherlands - Analysis of current methods for balancing, Ecofys, Un-numbered report.

de Boer W.W., Verheij F.J., Zwemmer D. \& Das R. (2007), The energy island - An inverse pump accumulation station, EWEC 2007, Milan, May 2007.

Brand A.J. (2006), Observed and predicted wind speed time series in the Netherlands and the North Sea, Energieonderzoek Centrum Nederland (ECN), Report ECN-C--06-007.

Brand A.J. \& Hegberg T. (2004), Offshore wind atlas, Energieonderzoek Centrum Nederland, Report ECN-CX--04-136.

Brand A.J. \& Kok J.K. (2003), Aanbodvoorspeller Duurzame Energie Deel 2: Korte-termijn prognose van windvermogen, Energieonderzoek Centrum Nederland, Report ECN-C03-049. 
von Bremen L., Tambke J., Saleck N. \& Heinemann D. (2006), Confidence in large-scale offshore wind farming: wind power predictability and stable grid integration of 25 GW German wind power, Proc. Sixth International Workshop on Large-Scale Integration of Wind Power and Transmission Networks for Offshore Wind Farms, Delft, October 2006, pp. 277-284.

Brockwell P.J. \& Davis R.A. (1991), Time Series: Theory and Methods (2nd ed.), Springer: New York, ISBN 0387974296.

Doherty R. \& O'Malley M. (2005), A new approach to quantify reserve demand in systems with significant installed wind capacity, IEEE Transactions on Power Systems 2005; 20, pp. 587-595.

Duguet B. \& Coelingh J. (2006), Simulated imbalance of 8000 MW wind power, Ecofys, Rapport Wind04071.

ETSO (2008), European Wind Integration Study (EWIS) - Towards a successful integration of wind power into European electricity grids, European Transmission System Operators, Final Report, www.etso-net.org (September 2009).

Gibescu M., Ummels B.C. \& Kling W.L. (2006), Statistical wind speed interpolation for simulating aggregated wind energy production under system studies, Proceedings of the 9th International Conference on Probabilistic Methods Applied to Power Systems, Stockholm, June 2006, 7 pp.

Gibescu M., Brand A.J. \& de Boer W.W. (2008a), System balancing with 6 GW offshore wind energy in the Netherlands - Instruments for balance control, Proc. Seventh International Workshop on Large-Scale Integration of Wind Power and Transmission Networks for Offshore Wind Farms, Madrid, April 2008, 7 pp.

Gibescu M., van Zwet E.W., Kling W.L. \& Christie R.D. (2008b), Optimal bidding strategy for mixed-portfolio producers in a dual imbalance pricing system, Proc. $16^{\text {th }}$ Power Systems Computation Conference, Glasgow, July 2008.

Gibescu M., Brand A.J. \& Kling W.L. (2009), Estimation of variability and predictability of large-scale wind energy in the Netherlands, Wind Energy, Volume 12 Issue 3, pp. 241-260.

Giebel G. (2000), On the benefits of distributed generation of wind energy in Europe, PhD Dissertation, Carl von Ossietzky University, Oldenburg.

Holttinen H. (2005), Hourly wind power variations in the Nordic countries, Wind Energy, Volume 8, pp. 173-195.

Krauss C., Gräber B., Lange M. \& Focken U. (2006), Integration of 18 GW wind energy into the energy market - Practical experiences in Germany, Proc. Sixth International Workshop on Large-Scale Integration of Wind Power and Transmission Networks for Offshore Wind Farms, Delft, October 2006, pp. 55-59.

Landberg L., Hansen M.A., Vesterager K. \& Bergstrom W. (1997), Implementing wind forecasting at a utility, Risø National Laboratory, Report Risø-R-929(EN).

Lange M. \& Focken U. (2005), Physical Approach to Short-Term Wind Power Production, Springer Verlag, Berlin, ISBN 3-540-25662-8.

Madsen H., Pinson P., Kariniotakis G., Nielsen H.A. \& Nielsen T.S. (2005), Standardizing the performance evaluation of short-term wind power prediction models, Wind Engineering, Vol. 29, No. 6, 2005, pp. 475-489. 
Norgard P., Giebel G., Holttinen H., Söder L. \& Petterteig A. (2004), Fluctuations and predictability of wind and hydro power, Risø National Laboratory, Report Risø-R1443(EN).

Norgard P. \& Holttinen H. (2004), A multi-turbine power curve approach, Nordic Wind Power Conference, Göteborg, 2004; 5 pp.

Söder L. (2004), Simulation of wind speed forecast errors for operation planning of multi-area power systems, International Conference on Probabilistic Methods Applied to Power Systems, Ames, 2004, pp. 723-728.

Ummels B.C., Gibescu M., Pelgrum E., Kling W.L. \& Brand A.J. (2007), Impacts of wind power on thermal generation unit commitment and dispatch, IEEE Transactions on Energy Conversion, Vol. 22, Issue 1, March 2007, pp. 44-51.

Ummels B.C., Pelgrum E. \& Kling W.L. (2008), Integration of large-scale wind power and use of energy storage in the Netherlands' electricity supply, IET Renewable Power Generation, 2(1), March 2008, pp. 34-46.

Verhaegen K., Ummels B.C., Belmans R.J.M. \& Kling W.L. (2006), Comparison of support schemes and market designs for wind power, Proc. Sixth International Workshop on Large-Scale Integration of Wind Power and Transmission Networks for Offshore Wind Farms, Delft, October 2006, pp. 39-47.

Walker J.F. \& Jenkins N. (1997), Wind Energy Technology. Wiley: New York, ISBN 0471960446.

Wolff M., Mackensen R., Füller G., Lange B., Rohrig K., Fischer F., Hofmann L., Heier S. \& Valov B. (2006), Advanced operating control for wind farm clusters, Proc. Sixth International Workshop on Large-Scale Integration of Wind Power and Transmission Networks for Offshore Wind Farms, Delft, October 2006, pp. 188-195. 


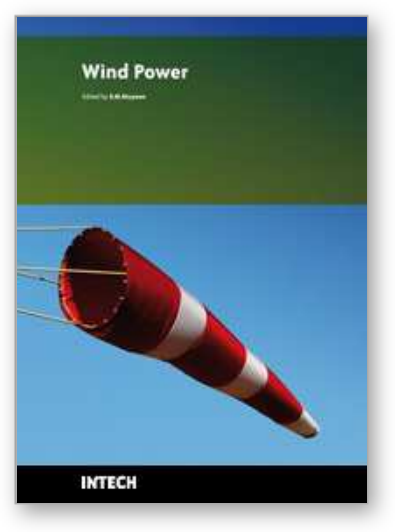

\author{
Wind Power \\ Edited by S M Muyeen
}

ISBN 978-953-7619-81-7

Hard cover, 558 pages

Publisher InTech

Published online 01, June, 2010

Published in print edition June, 2010

This book is the result of inspirations and contributions from many researchers of different fields. A wide verity of research results are merged together to make this book useful for students and researchers who will take contribution for further development of the existing technology. I hope you will enjoy the book, so that my effort to bringing it together for you will be successful. In my capacity, as the Editor of this book, I would like to thanks and appreciate the chapter authors, who ensured the quality of the material as well as submitting their best works. Most of the results presented in to the book have already been published on international journals and appreciated in many international conferences.

\title{
How to reference
}

In order to correctly reference this scholarly work, feel free to copy and paste the following:

A.J. Brand, M. Gibescu and W.W. de Boer (2010). Variability and Predictability of Large-Scale Wind Energy in the Netherlands, Wind Power, S M Muyeen (Ed.), ISBN: 978-953-7619-81-7, InTech, Available from:

http://www.intechopen.com/books/wind-power/variability-and-predictability-of-large-scale-wind-energy-in-thenetherlands

\section{INTECH}

open science | open minds

\section{InTech Europe}

University Campus STeP Ri Slavka Krautzeka 83/A 51000 Rijeka, Croatia

Phone: +385 (51) 770447

Fax: +385 (51) 686166 www.intechopen.com

\section{InTech China}

Unit 405, Office Block, Hotel Equatorial Shanghai No.65, Yan An Road (West), Shanghai, 200040, China 中国上海市延安西路65号上海国际贵都大饭店办公楼405单元 Phone: +86-21-62489820

Fax: +86-21-62489821 
(C) 2010 The Author(s). Licensee IntechOpen. This chapter is distributed under the terms of the Creative Commons Attribution-NonCommercialShareAlike-3.0 License, which permits use, distribution and reproduction for non-commercial purposes, provided the original is properly cited and derivative works building on this content are distributed under the same license. 